\title{
Prediction of Cerebral Amyloid Pathology Based on Plasma Amyloid and Tau Related Markers
}

\author{
Ting-Bin Chen 1,2,3, Kun-Ju Lin ${ }^{4,5}$, Szu-Ying Lin ${ }^{6}$, Yi-Jung Lee ${ }^{7}$, Yi-Cheng Lin ${ }^{6,8}$, \\ Chen-Yu Wang ${ }^{9}$, Jun-Peng Chen ${ }^{10}$ and Pei-Ning Wang ${ }^{9,11,12 *}$
}

${ }^{1}$ Department of Neurology, Neurological Institute, Taichung Veterans General Hospital, Taichung, Taiwan, ${ }^{2}$ Dementia Center, Taichung Veterans General Hospital, Taichung, Taiwan, ${ }^{3}$ Center for Geriatrics and Gerontology, Taichung Veterans General Hospital, Taichung, Taiwan, ${ }^{4}$ Department of Nuclear Medicine and Molecular Imaging Center, Linkou Chang Gung Memorial Hospital, Taoyuan, Taiwan, ${ }^{5}$ Healthy Aging Research Center and Department of Medical Imaging and Radiological Sciences, College of Medicine, Chang Gung University, Taoyuan, Taiwan, ${ }^{6}$ Taipei Municipal Gan-Dau Hospital, Taipei, Taiwan, ${ }^{7}$ Division of Neurology, Department of Medicine, Taipei City Hospital Renai Branch, Taipei, Taiwan, ${ }^{8}$ School of Life Sciences, Institute of Neuroscience, National Yang-Ming University, Taipei, Taiwan, ${ }^{9}$ Division of General Neurology, Department of Neurological Institute, Taipei Veterans General Hospital, Taipei, Taiwan, ${ }^{10}$ Biostatistics Task Force of Taichung Veterans General Hospital, Taichung, Taiwan, ${ }^{11}$ Faculty of Medicine, School of Medicine, National Yang Ming Chiao Tung University, Taipei, Taiwan, ${ }^{12}$ Brain Research Center, National Yang Ming Chiao Tung University, Taipei, Taiwan

\section{OPEN ACCESS}

Edited by:

Ching-Kuan Liu,

Kaohsiung Medical University

Hospital, Taiwan

Reviewed by:

Michael D. Devous,

Avid Radiopharmaceuticals, Inc.,

United States

Sam Gandy,

Icahn School of Medicine at Mount

Sinai, United States

${ }^{*}$ Correspondence:

Pei-Ning Wang

linda2860@gmail.com

Specialty section:

This article was submitted to Dementia and Neurodegenerative

Diseases,

a section of the journal

Frontiers in Neurology

Received: 20 October 2020 Accepted: 07 September 2021

Published: 04 October 2021

Citation:

Chen T-B, Lin K-J, Lin S-Y, Lee Y-J, Lin $Y-C$, Wang $C-Y$, Chen J-P and

Wang P-N (2021) Prediction of Cerebral Amyloid Pathology Based on

Plasma Amyloid and Tau Related

Markers. Front. Neurol. 12:619388.

doi: 10.3389/fneur.2021.619388
Background and Purpose: Pyroglutamate-modified $\beta$-amyloid peptide $\left(A \beta_{p E}\right)$ is crucial for $A D$ pathophysiological process. The potential associations of plasma $A \beta_{p E}$ and total tau (t-tau) with brain A $\beta$ burden and cognitive performance remain to be clarified.

Methods: Forty-six subjects with unimpaired cognition, mild cognitive impairment, or very mild dementia were enrolled. Plasma levels of $A \beta_{p E 3-40}$, t-tau, and $A \beta 42$ were quantified by immunomagnetic reduction (IMR) assays. We analyzed individual and combined biomarker correlations with neuropsychological scores and $A \beta$ positivity determined by ${ }^{18} \mathrm{~F}$-florbetapir positron emission tomography (PET).

Results: Both plasma $A \beta_{p E 3-40}$ levels and $A \beta_{p E 3-40} / t$-tau ratios correlated negatively with short-term memory and global cognition scores, while correlating positively with PET standardized uptake value ratios (SUVRs). Among the biomarkers analyzed, the combination of $A \beta_{p E 3-40}$ in a ratio with t-tau had the best discriminatory ability for $A \beta P E T$

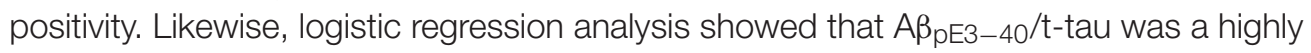
robust predictor of $A \beta P E T$ positivity after controlling for relevant demographic covariates.

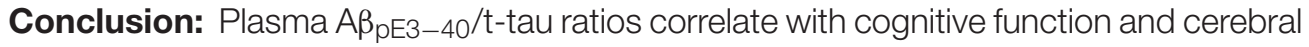
$A \beta$ burden. The suitability of $A \beta_{\mathrm{PE} 3-40} / \mathrm{t}$-tau as a candidate clinical biomarker of $A D$ pathology in the brain should be examined further in larger studies.

Keywords: pyroglutamate, tau, $\beta$-amyloid, Alzheimer's disease, predictor

\section{INTRODUCTION}

Alzheimer's disease $(\mathrm{AD})$ underlies a major unmet medical need in routine clinical practice and casts a considerable burden on patients, caregivers, and societies. The neuropathological characteristics of $\mathrm{AD}$ include neuronal loss, $\beta$-amyloid $(\mathrm{A} \beta)$ plaques, neurofibrillary tangles, and synaptic loss $(1,2)$. 
The main $A \beta$ variants detected in the human brain are $\mathrm{A} \beta 40$ and $\mathrm{A} \beta 42$. They are found together with $\mathrm{N}$-terminal truncated forms of these variants $(A \beta n-40 / 42)$, which have been shown to have pyroglutamate modifications, yielding a distinct pyroglutamate-modified $A \beta$ peptide $\left(A \beta_{p E}\right)$ (3-6). The $\mathrm{A} \beta_{\mathrm{pE}}$ peptide has been identified in early-stage $\mathrm{AD}$, even before clinical symptoms are apparent, implicating it as a potential seeding molecule that may enable pathological $A \beta$ aggregate formation and triggering hyperphosphorylation of tau (6-11). $\mathrm{A} \beta_{\mathrm{pE}}$ is formed when full-length $\mathrm{A} \beta$ peptides undergo truncation at the $\mathrm{N}$-terminal glutamate and subsequent dehydration catalyzed by glutaminyl cyclase $(12,13)$. Compared to full-length peptides, $\mathrm{A} \beta_{\mathrm{pE}}$ displays greater $\beta$-sheet content, hydrophobicity, aggregation propensity, deposition, amyloidogeneity, resistance to enzymatic degradation, and neuronal toxicity $(9,14-17)$. In addition, $\mathrm{A} \beta_{\mathrm{pE}}$ has been reported to be closely associated with cognitive decline, disease progression, and cerebral amyloidosis in $\operatorname{AD}(8,10,18,19)$, suggesting that it may be a key driving force in $\mathrm{AD}$ pathogenesis.

Amyloidosis, a primary characteristic of $\mathrm{AD}$ pathology, can be detected by positron emission tomography (PET) imaging and cerebrospinal fluid (CSF) measures $(20,21)$. Both measures possess high diagnostic and prognostic value and may reveal changes many years prior to clinical onset of $\mathrm{AD}$ (22-25). Because PET scans are costly and have limited availability, they cannot be incorporated broadly into routine clinical assessments of cognitive impairment before initiation of $\mathrm{AD}$ treatment therapies. By contrast, although CSF sampling is less costly and more readily available, it is quite invasive. Neither the PET nor the CSF test is appropriate for population-based screening aimed at identifying high-risk individuals before symptom onset. Moreover, approximately $70 \%$ of study participants with clinical syndromes of $\mathrm{AD}$ dementia in $\mathrm{AD}$ prevention trials and around $25 \%$ of participants in $\mathrm{AD}$ drug trials did not have brain amyloidosis that was detectable by $\operatorname{PET}(26,27)$. Thus, a minimally invasive measure, such as a blood test, that can reflect cerebral $\mathrm{AD}$ pathology accurately and reliably would have critical advantages for supporting clinical decisions regarding $\mathrm{AD}$ treatment planning and monitoring of patients during therapeutic trials.

Immunomagnetic reduction (IMR) assay is a relatively new ultrasensitive detection technology capable of quantifying biomarkers down to $\mathrm{pg} / \mathrm{mL}$ levels. Previously, we observed a positive correlation of IMR-quantified plasma levels of a pyroglutamate cyclization variant of $\mathrm{N}$-terminally truncated $\mathrm{A} \beta 3-40\left(\mathrm{~A} \beta_{\mathrm{pE} 3-40}\right)$ with cerebral amyloidosis detected by PET imaging (18). In the present study, IMR was implemented to measure plasma levels of $A \beta_{\mathrm{pE} 3-40}$, t-tau, and $A \beta 42$. The primary aim of this work was to investigate associations of these plasma biomarkers, individually and in combination, with cognitive performance and to assess their utility for predicting A $\beta$ PET positivity $(+)$.

\section{MATERIALS AND METHODS}

\section{Subjects}

Eligible subjects at Taipei Veterans General Hospital, Linkou Chang Gung Memorial Hospital, and Kaohsiung Chang Gung
Memorial Hospital were enrolled through the Alzheimer's Disease Neuroimaging Initiative in Taiwan (T-ADNI). The local institutional review boards and the ethics committee of the three hospitals approved the data collection protocol. T-ADNI study was approved by the ethics committees of the three hospitals. The inclusion criteria were an age of 55 to 90 years and educational attainment of at least 6 years. Prior to testing, written informed consent was obtained from all participants and/or their legal guardians. All methods were performed in accordance with the relevant guidelines and regulations.

All participants were interviewed by experienced neurologists to collect information about their demographics, family history, and physical/neurological condition. Additionally, for each participant, neurologists obtained Hachinski ischemic score and vital signs. Blood was drawn for a hematology/chemistry panel and for vitamin B12s, thyroid-stimulating hormone, free thyroxine, and rapid plasma reagin syphilis tests.

A standard battery of neuropsychological tests was administered, including the Geriatric Depression Scale, Mini-Mental State Examination (MMSE) (28), Chinese Version Verbal Learning Test (29), Logical Memory subscale (story A) of the Chinese version of the Wechsler Memory Scale-III (30), 30-item Boston Naming Test (31), categorical Verbal Fluency Test (29), Trail-Making Test A and B (line) (32), and Clinical Dementia Rating Scale (CDR) (33). Only subjects with non-impaired cognition, defined by CDR score of 0 , and patients in the prodromal stage or very mild dementia stage, defined by CDR score of 0.5 , were invited to participate in this study.

Signs of cognitive impairment were assessed and non-AD etiologies (e.g., tumors, strokes, severe white matter disease, or inflammation) were excluded through a series of clinical interviews, a physical examination, screening laboratory tests, neuropsychological assessments, and brain magnetic resonance (MR) imaging. Exclusionary criteria included any history of major brain trauma, brain tumor, stroke, epilepsy, alcoholism, major psychiatric illness, or any other systemic diseases that might affect cognitive function. Diagnosis of amnestic mild cognitive impairment and probable $\mathrm{AD}$ were made on the basis of the core clinical criteria developed by the National Institute on Aging and the Alzheimer's Association's 2011 workgroup (NIAAA) (34). The demographic characteristics of the study cohort, dichotomized according to A $\beta$ PET results, are summarized in Table 1.

\section{Collection and Preparation of Human Plasma Samples}

An 8-ml non-fasting venous blood sample (K3 EDTA, lavendertop tube) was collected from each subject and then centrifuged $(1,500-2,500 \times g$ for $15 \mathrm{~min})$ within $1 \mathrm{~h}$ of the draw. The plasma was then aliquoted into cryotubes and stored at $-20^{\circ} \mathrm{C}$.

\section{IMR Measurements}

Detailed descriptions of the IMR platform and validation of its accuracy have been published previously $(18,35)$. IMR reagents were selected based on epitope antigen/antibody affinity, ability to conjugate with $\mathrm{MagQu}$ magnetic $\mathrm{Fe}_{3} \mathrm{O}_{4}$ nanobeads, and ability to produce linear standard curves of quantitated magnetic signal reduction. Each type of reagent consists of 
TABLE 1 | Demographic and clinical characteristics of enrolled subjects $(N=46)$.

\begin{tabular}{|c|c|c|c|}
\hline Characteristic & A $\beta$ PET $-(N=28)$ & $\mathrm{A} \beta \mathrm{PET}+(N=18)$ & $\boldsymbol{P}$ \\
\hline Female/male ratio & $11 / 17$ & $11 / 7$ & $>0.999$ \\
\hline Age, years & $69.5(60.3-77.3)$ & $72.0(64.0-78.3)$ & 0.373 \\
\hline Education, years & $12.0(9.0-15.0)$ & $13.0(11.3-16.0)$ & 0.273 \\
\hline Clinical stage & & & 0.005 \\
\hline $\mathrm{HC}$ & 5 & 0 & \\
\hline $\mathrm{aMCl}$ & 18 & 7 & \\
\hline$A D$ & 5 & 11 & \\
\hline ApoE e4 allele carrier & $7.7 \%$ & $25 \%$ & 0.038 \\
\hline MMSE & $27.5(25.3-29.0)$ & $23.5(22.0-26.3)$ & 0.001 \\
\hline CDR & & & 0.072 \\
\hline 0 & 5 & 0 & \\
\hline 0.5 & 23 & 18 & \\
\hline Global SUVR & $1.1(1.0-1.2)$ & $1.5(1.4-1.7)$ & $<0.001$ \\
\hline$A \beta_{p E 3-40}, f g / m L$ & $42.3(19.0-60.7)$ & 65.7 (54.3-118.6) & 0.003 \\
\hline t-tau, pg/mL & $21.3(13.9-30.6)$ & $14.9(13.2-18.3)$ & 0.072 \\
\hline$A \beta 42, \mathrm{pg} / \mathrm{mL}$ & $17.3(14.8-19.4)$ & $15.3(14.9-16.5)$ & 0.115 \\
\hline $\mathrm{A} \beta_{\mathrm{pE} 3-40} / \mathrm{t}-\mathrm{tau}$ & $1.72(0.734-3.174)$ & 4.39 (2.683-9.091) & 0.001 \\
\hline A $\beta 42 /$ t-tau & $0.8(0.7-1.0)$ & $1.0(0.7-1.1)$ & 0.9 \\
\hline
\end{tabular}

PET, positron emission tomography; $H C$, healthy control; aMCl, amnestic mild cognitive impairment; $A D$, Alzheimer's disease; $C D R$, clinical dementia ranking; MMSE, mini-mental state examination; SUVR, standardized uptake value ratio.

Continuous variables, presented as median (interquartile range), were analyzed with Mann-Whitney $U$ tests. Categorical variables, presented as number of subjects or percentage, were examined by a Chi-square test.

magnetic nanoparticles dispersed in phosphate buffered saline ( $\mathrm{pH}$ 7.2). By immobilizing functionalized monoclonal antibodies against AB37-42 (ABCAM, Cambridge, UK; ab34376) and t-tau protein (Sigma Aldrich; T9450) on the magnetic nanoparticles, two types of reagents were obtained. The antibody against $\mathrm{A} \beta_{\mathrm{pE} 3-40}$ was developed by Biogen Inc. The mean diameter of the antibody-functionalized magnetic nanoparticles was 50$60 \mathrm{~nm}$. The magnetic concentration of each type of reagent was $12 \mathrm{mg}-\mathrm{Fe} / \mathrm{mL}$. Duplicated/paired measurements of $\mathrm{A} \beta 42$, $\mathrm{A} \beta_{\mathrm{pE} 3-40}$, and t-tau were performed for each plasma sample. We mixed 60- $\mu \mathrm{l}$ plasma samples with $60 \mu \mathrm{l}$ of reagent (MFAB2-0060 or MF-DEX-0060, respectively; MagQu) at room temperature in the $\mathrm{A} \beta 42$ and $\mathrm{A} \beta_{\mathrm{pE} 3-40}$ assays; for the t-tau assay, $40 \mu \mathrm{l}$ of plasma with $80 \mu \mathrm{l}$ of reagent (MF-TAU-0060; $\mathrm{MagQu}$ ) were used. Magnetic signal changes during the course of interactions between antigens and antibody-functionalized magnetic nanoparticles were detected by an IMR reader (XacPro-S, MagQu) and expressed as percentage reductions in immunomagnetic signal, which were then converted to a sample concentration based on reference to standard curves of the respective analytes. The ratio of the reduction to the alternativecurrent (ac) magnetic signal of reagent before incubation is expressed as follows:

$$
\operatorname{IMR}(\%)=\frac{\chi_{a c, o}-\chi_{a c, \phi}}{\chi_{a c, o}} \times 100 \%
$$

where $\chi_{\mathrm{ac}, 0}$ and $\chi_{\mathrm{ac}, \phi}$ are the ac magnetic signals of reagent before and after incubation. For each reported IMR (\%) in this study, an averaged value of duplicated IMR measurements was calculated. The standard deviations of all duplicated plasma analyte measurements were $<15 \%$. The reported analyte concentrations for each sample are means of the paired measurements.

\section{Analysis of ApoE Genotypes}

ApoE genotyping was determined by polymerase chain reaction amplification and DNA sequencing (36). Participants with one or two $\varepsilon 4$ alleles were defined as $\varepsilon 4$ carriers.

\section{A $\beta$ PET Imaging Data Acquisition}

All A $\beta$ PET imaging scans were performed on a Biograph mCT PET/CT scanner (GE Healthcare, Milwaukee, WI) at a single site (Linkou Chang Gung Memorial Hospital) as described in detail elsewhere $(37,38)$. Briefly, the scan commenced with a 10-min acquisition period (two 5-min frames) beginning 50-min after a $10-\mathrm{mCi}$ injection of ${ }^{18} \mathrm{~F}$-florbetapir tracer. Each image was obtained with the application of a three-dimensional ordered subset expectation maximization reconstruction algorithm (four iterations, 24 subsets; Gaussian filter: $2 \mathrm{~mm}$; zoom: three) with computed tomography-based attenuation correction, as well as scatter and random corrections, with a matrix size of $400 \times 400$ $\times 148$ and a voxel size of $0.68 \times 0.68 \times 1.5 \mathrm{~mm}^{3}$. To achieve useful anatomical information and facilitate co-registration with PET images, structural MR scans were obtained for all subjects with a uniform scanning protocol that minimizes and accounts for between-site differences in MR imaging systems.

\section{A $\beta$ PET Imaging Processing}

PET imaging data were processed and analyzed in PMOD software (version 3.7, PMOD Technologies Ltd., Zurich, Switzerland), including MR-based spatial normalization to the Montreal Neurological Institute MRI template. We selected seven volumes of interest: frontal, anterior cingulate, posterior cingulate, precuneus, parietal, occipital, and temporal cortical areas. We calculated regional standardized uptake value ratios (SUVRs) for each volume of interest, using the whole cerebellum as a reference region, and then averaged the SUVRs for the seven volumes of interest to yield an estimated global cortical SUVR value for further analysis.

All the PET images were interpreted by an experienced nuclear medicine physician (Kun-Ju Lin) who did not have access to clinical data. $A \beta$ burden was graded on a five-point visual scale, from 0 , indicating no tracer retention in cortical gray matter, to 4 , denoting high levels of cortical amyloid accumulation. Scores of 0 or 1 were categorized as A $\beta$ PET negativity (-) and scores of $2-4$ were categorized as A $\beta$ PET + (39).

\section{Statistical Methods}

All statistical analyses were performed in SPSS version 22.0 for Windows (SPSS Inc., Chicago, IL, USA). A $P<0.05$ was considered significant. All variables were analyzed by non-parametric methods. For continuous variables, differences between $\mathrm{A} \beta$ PET- group and A $\beta$ PET+ group were detected with Mann-Whitney U tests. For categorical variables, Chi-square 
tests were used. We generated neurocognitive numeric composite $\mathrm{z}$-scores by calculating individual $\mathrm{z}$-scores for each test and then averaging them across the cognitive test set. The constituents of the composite z-scores were as follows: short-term memory [Chinese Version Verbal Learning Test and Logical Memory subscale (story A) of the Chinese Version Wechsler Memory Scale-III], semantic memory [Boston Naming Test (total)]; executive function [Trail-Making Test-A/B (line) and categorical Verbal Fluency Test (animal)]; global cognition [short-term memory test, semantic memory test, executive function test, and the MMSE]. Spearman's rank coefficients were calculated to determine correlation of plasma biomarker levels with estimated global cortical SUVR and domains of cognitive performance. Receiver operating characteristic (ROC) and area under the curve (AUC) analyses were performed to define cut-off points for each biomarker analyte or their ratios to further characterize discriminatory properties between the $\mathrm{A} \beta$ PET- and $\mathrm{A} \beta$ PET+ groups. Finally, logistic regression modeling was performed to investigate the predictive power of biomarker levels for $A \beta$ PET + , in terms of odds ratios (ORs) and 95\% confidence interval (CIs), with and without adjusting for age, sex, and ApoE $\varepsilon 4$ carrier status.

\section{RESULTS}

\section{Demographic Data}

A total of 46 subjects were enrolled in the study and divided into $\mathrm{A} \beta$ PET- and $\mathrm{A} \beta$ PET + groups. Their demographic characteristics and neurocognitive scores are presented in Table 1. There were no significant between-group differences in age, sex, years of education, clinical stage or CDR scores, nor in plasma biomarker levels of $t$-tau, $A \beta 42$, or $A \beta 42 / t$-tau. Compared to the $\mathrm{A} \beta$ PET- group, the $\mathrm{A} \beta \mathrm{PET}+$ group had more ApoE $\varepsilon 4$ carriers ( $25 \%$ vs. $7.7 \%, p=0.038)$, poorer performance on MMSE (23.5 vs. $27.5, p=0.001$ ), higher A $\beta$ PET SUVR (1.5 vs. $1.1, p<$ 0.001 ), and higher levels of plasma $\mathrm{A} \beta_{\mathrm{pE} 3-40}$ (65.7 vs. $42.3, p=$ 0.003 ) and $\mathrm{A} \beta_{\mathrm{pE} 3-40} / \mathrm{t}$-tau ratio (4.39 vs. $\left.1.72, p=0.001\right)$.

\section{Association of Plasma Biomarkers With $\mathbf{A} \beta$ Burden and Cognitive Performance}

$\mathrm{A} \beta_{\mathrm{pE} 3-40}$ level $(\mathrm{r}=0.343, p<0.005)$, and $\mathrm{A} \beta_{\mathrm{pE} 3-40} / \mathrm{t}$-tau ratio values $(r=0.305, p<0.005)$ correlated directly with A $\beta$ PET SUVRs (Table 2; Figure 1). Short-term memory scores correlated negatively with $\mathrm{A} \beta_{\mathrm{pE} 3-40}(\mathrm{r}=-0.481, p<0.001)$ and $\mathrm{A} \beta_{\mathrm{pE} 3-40} / \mathrm{t}$-tau values $(\mathrm{r}=-0.483, p<0.001)$, but positively with $\mathrm{t}$-tau $(\mathrm{r}=0.3, p<0.005)$ and A $\beta 42$ levels $(\mathrm{r}=0.391, p<0.001)$. Semantic memory scores were found to correlate positively with A 342 levels $(r=0.353, p<0.005)$, while executive function scores correlated positively with $\mathrm{A} \beta_{\mathrm{pE} 3-40} / \mathrm{t}$-tau values $(\mathrm{r}=$ $0.359, p<0.005)$. Global cognition scores correlated negatively with $\mathrm{A} \beta_{\mathrm{pE} 3-40}(\mathrm{r}=-0.337, p<0.005)$ and $\mathrm{A} \beta_{\mathrm{pE} 3-40} / \mathrm{t}$-tau values $(\mathrm{r}=-0.343, p<0.005)$ while correlating positively with $\mathrm{A} \beta 42$ levels $(r=0.379, p<0.005)$.

\section{ROC Analysis for Prediction of A $\beta$ PET Positivity}

ROC-AUC analyses aimed at determining plasma biomarker discriminatory cut-off values yielded the following optimal significant cut-off values for the differentiation of $\mathrm{A} \beta$ PET- and $\mathrm{A} \beta$ PET+ groups: $55.45 \mathrm{fg} / \mathrm{mL}$ for $\mathrm{A} \beta_{\mathrm{pE} 3-40} ; 2.85$ for $\mathrm{A} \beta_{\mathrm{pE} 3-40} / \mathrm{t}-$ tau; and 0.8 for $A \beta 42 / t$-tau. The combination of $A \beta_{\mathrm{pE} 3-40}$ with $\mathrm{t}$-tau in a $\mathrm{A} \beta_{\mathrm{pE} 3-40} / \mathrm{t}$-tau ratio had a greater $\mathrm{AUC}$ than individual biomarkers (i.e., $\mathrm{A} \beta_{\mathrm{pE} 3-40}$, t-tau, and $\mathrm{A} \beta 42$ ) and the composite A $342 / t$-tau ratio. Detailed AUCs, cut-off values, sensitivities, and specificities are reported in Table 3.

\section{Association of Plasma Biomarkers With A $\beta$ PET Positivity}

The relationship between plasma biomarkers and A $\beta$ PET positivity was examined through a logistic regression analysis with the aforementioned optimal cut-offs. All of the analyzed markers were found to be significantly associated with A $\beta$ PET positivity risk in both the unadjusted and adjusted logistic regression modeling results (Table 4). All adjusted ORs (aORs) became more pronounced after controlling for age, sex, and ApoE $\varepsilon 4$ carrier status. Participants with $\mathrm{A} \beta_{\mathrm{pE} 3-40}>55.45$ $\mathrm{fg} / \mathrm{mL}$, $\mathrm{t}$-tau $\leq 19.10 \mathrm{pg} / \mathrm{mL}, \mathrm{A} \beta 42 \leq 16.27 \mathrm{pg} / \mathrm{mL}, \mathrm{A} \beta_{\mathrm{pE} 3-40} / \mathrm{t}-$ tau $>2.85$, or $\mathrm{A} \beta 42 / \mathrm{t}$-tau $>0.8$ were at increased risk for $\mathrm{A} \beta$ PET positivity (aOR, 95\% CI, and $p$-values are reported in Table 4).

\section{DISCUSSION}

The current study assessed the association of levels of $\mathrm{AD}$ related biomarkers, especially $\mathrm{A} \beta_{\mathrm{pE} 3-40}$, quantified by IMR technology with cognitive performance as well as their predictive power in $\mathrm{A} \beta$ PET positivity. We found that participants with $\mathrm{A} \beta \mathrm{PET}+$ had higher levels of plasma $\mathrm{A} \beta_{\mathrm{pE} 3-40}$ and higher $\mathrm{A} \beta_{\mathrm{pE} 3-40} / \mathrm{t}$-tau ratio values than participants with $\mathrm{A} \beta$ PET-. These elevated values correlated positively with PET analysis findings and correlated negatively with short-term memory and global cognition scores. $\mathrm{A} \beta_{\mathrm{pE} 3-40}$ alone had a high discriminatory ability, and consideration of $\mathrm{A} \beta_{\mathrm{pE} 3-40}$ together with t-tau (i.e., in $\mathrm{A} \beta_{\mathrm{pE} 3-40} / \mathrm{t}$-tau) provided greater differential value than any of the individual biomarker values examined and the $A \beta 42 / t$-tau ratio. After adjusting for demographic covariates (age, sex, and ApoE $\varepsilon 4$ carrier status), $\mathrm{A} \beta_{\mathrm{pE} 3-40} / \mathrm{t}$-tau proved to be the strongest predictive biomarker for $\mathrm{A} \beta$ PET positivity. Collectively, these findings suggest that plasma $A \beta_{\mathrm{pE} 3-40} / \mathrm{t}$-tau may indeed be reflective of cerebral amyloid pathology. To the best of our knowledge, the current study is the first to report relationships among plasma t-tau level, plasma $A \beta_{\mathrm{pE} 3-40}$ level, and brain $\mathrm{A} \beta$ accumulation revealed by in vivo PET.

In a previous study, we observed a positive association of $\mathrm{A} \beta_{\mathrm{pE} 3-40}$ levels with $\mathrm{A} \beta$ PET SUVRs (18). In this study, we affirmed those prior findings and further showed that $\mathrm{A} \beta_{\mathrm{pE} 3-40^{-}}$ related biomarkers were more closely related to brain $A \beta$ accumulation revealed by $\mathrm{A} \beta$ PET than were $\mathrm{A} \beta 42$, $\mathrm{t}$-tau, and A $\beta 42 / t$-tau values. These results are discordant with previous data obtained with ultrasensitive analytical assays-such as, 
TABLE 2 | Correlation of plasma biomarkers with $A \beta$ burden and cognitive performance $(N=46)$.

\begin{tabular}{|c|c|c|c|c|c|}
\hline A $\beta$ PET biomarker & \multicolumn{5}{|c|}{ Spearman $r_{s}$} \\
\hline t-tau & -0.041 & $0.300^{*}$ & 0.286 & -0.248 & 0.305 \\
\hline Aß42 & -0.007 & $0.391^{\star *}$ & $0.353^{*}$ & -0.216 & $0.379^{*}$ \\
\hline $\mathrm{A} \beta_{\mathrm{pE} 3-40} / \mathrm{t}-\mathrm{tau}$ & $0.305^{*}$ & $-0.483^{\star \star}$ & -0.140 & $0.359^{\star}$ & $-0.343^{\star}$ \\
\hline
\end{tabular}

SUVR, standardized uptake value ratio.

${ }^{*} p<0.05,{ }^{* *} p<0.01$.
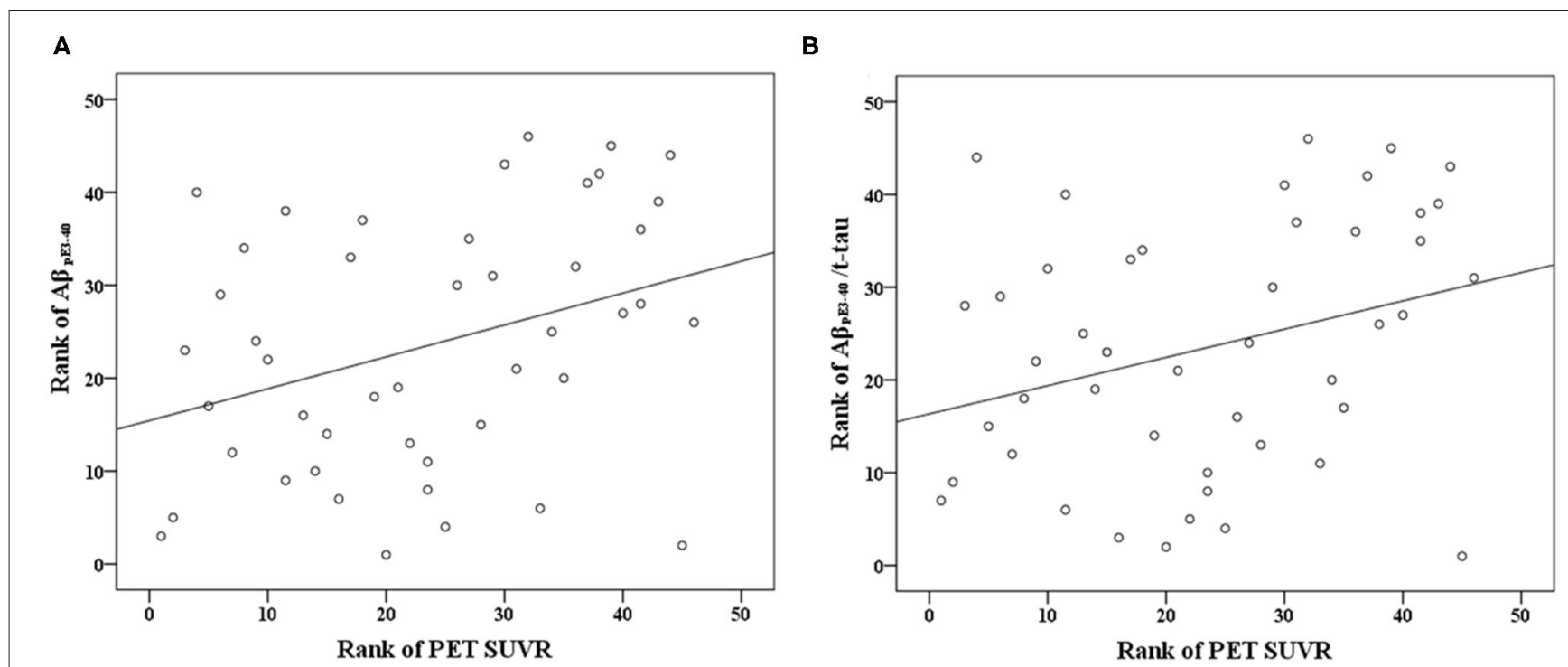

FIGURE 1 | Scatterplots of the associations between $A \beta$ PET SUVR and plasma biomarker levels $(\mathrm{pg} / \mathrm{mL})$ of (A) $A \beta_{p E 3-40}$ and (B) $A \beta_{p E 3-40} / t-t a u$.

TABLE 3 | ROC analysis for identifying A $\beta$ PET positivity $(N=46)$.

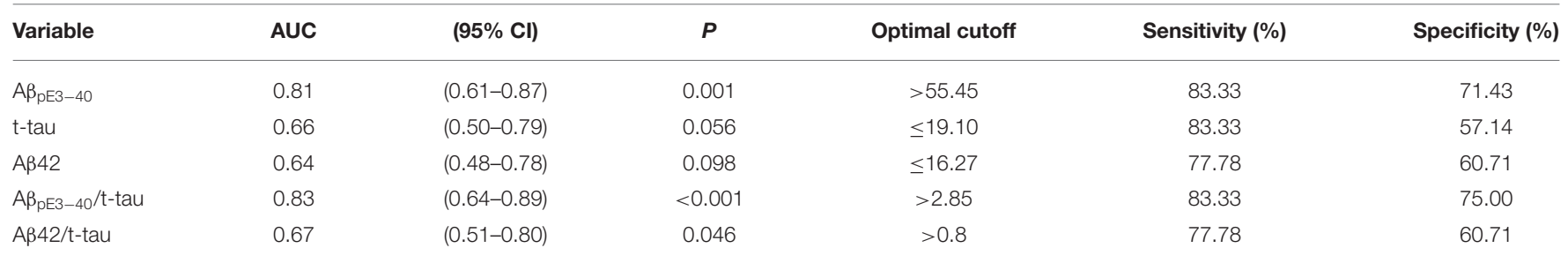

AUC, area under the curve; ROC, receiver operator characteristic curve.

xMAP, stable isotope labeling kinetics-mass spectrometry, singlemolecule array, and immunoprecipitation mass spectrometry approaches-showing that lower plasma A $\beta 42$ levels and $\mathrm{A} \beta 42 / \mathrm{A} \beta 40$ ratios were associated with a higher brain $\mathrm{A} \beta$ burden revealed by $\mathrm{A} \beta$ PET over the normal-mild cognitive impairment-AD cognitive spectrum (40-48). This divergence of findings could be consequent to the critically discrepant roles of $\mathrm{A} \beta_{\mathrm{pE}}$ and $\mathrm{A} \beta 42$ in $\mathrm{AD}$ pathophysiological processes. $\mathrm{A} \beta_{\mathrm{pE}}$ has been considered to be a principal initiator of early-stage $\mathrm{AD}$ pathogenesis and has been shown to correlate with tau pathology and cognitive decline in $\operatorname{AD}(10,12,15,19,49)$, whereas plasma $A \beta 42$ was found to be inversely correlated with cortical $A \beta$ burden, likely due to impaired $A \beta$ plaque clearance from the brain or sequestration and deposition of $A \beta$ species within the brain. A recent animal study showed the evidence that impaired meningeal lymphatic drainage can exacerbate the neuroinflammatory response and enhancing meningeal lymphatic function could achieve better ability of monoclonal antibodies to clear $\mathrm{A} \beta$ aggregates (50). Together with a phase 2 trial revealing that donanemab, a monoclonal antibody against 
TABLE 4 | Association of plasma biomarkers with A $\beta$ PET positivity $(N=46)$.

\begin{tabular}{|c|c|c|c|c|c|c|}
\hline \multirow{2}{*}{$\begin{array}{l}\text { Plasma markers } \\
\text { Cut-off groups }\end{array}$} & \multicolumn{3}{|c|}{ Unadjusted } & \multicolumn{3}{|c|}{ Adjusted $^{\mathrm{a}}$} \\
\hline & OR & $95 \% \mathrm{Cl}$ & $P$ & OR & $95 \% \mathrm{Cl}$ & $P$ \\
\hline \multicolumn{7}{|l|}{$A \beta_{p E 3-40}, f g / m L$} \\
\hline$\leq 55.45$ & & Reference & & & Reference & \\
\hline$>55.45$ & 12.36 & $(2.36-64.64)$ & 0.003 & 21.75 & $(2.38-198.79)$ & 0.006 \\
\hline \multicolumn{7}{|l|}{ t-tau, pg/mL } \\
\hline$>19.10$ & & Reference & & & Reference & \\
\hline$\leq 19.10$ & 6.66 & (1.56-25.0) & 0.010 & 16.66 & $(1.96-100.2)$ & 0.011 \\
\hline \multicolumn{7}{|l|}{$\mathrm{A} \beta 42, \mathrm{pg} / \mathrm{mL}$} \\
\hline$>16.27$ & & Reference & & & Reference & \\
\hline$\leq 16.27$ & 5.55 & $(1.41-20.0)$ & 0.014 & 16.66 & $(1.85-100.1)$ & 0.012 \\
\hline \multicolumn{7}{|l|}{$\mathrm{A} \beta_{\mathrm{pE} 3-40} / \mathrm{t}-\mathrm{tau}$} \\
\hline$\leq 2.85$ & & Reference & & & Reference & \\
\hline$>2.85$ & 10.50 & $(2.58-42.68)$ & 0.001 & 33.98 & $(3.37-342.83)$ & 0.003 \\
\hline \multicolumn{7}{|l|}{ A $\beta 42 / t-t a u$} \\
\hline$\leq 0.8$ & & Reference & & & Reference & \\
\hline$>0.8$ & 5.41 & $(1.41-20.77)$ & 0.014 & 18.97 & (2.04-176.34) & 0.010 \\
\hline
\end{tabular}

$\mathrm{Cl}$, confidence interval; OR, odds ratio. ${ }^{a}$ Adjusted for age, sex, and ApoE e4 allele status.

$\mathrm{A} \beta_{\mathrm{pE}}$ epitope, could curb cognitive decline in early $\mathrm{AD}$ (51), we speculate that $A \beta_{\mathrm{pE} 3-40}$ is a better plasma biomarker than $A \beta 42$ for detection and monitoring of cerebral amyloidosis.

We found that $\mathrm{A} \beta_{\mathrm{pE} 3-40}, \mathrm{~A} \beta 42$, and $\mathrm{A} \beta_{\mathrm{pE} 3-40} / \mathrm{t}$-tau correlated significantly with short-term memory and global cognition performance measures, whereas t-tau and $A \beta 42 / t$-tau did not correlate well with any cognitive performance measures in our study. $\mathrm{A} \beta_{\mathrm{pE} 3-40}$ has specifically been found to be more cytotoxic to hippocampal and cortical neurons than $A \beta 40$ and $A \beta 42$ in animal studies (52, 53), highlighting the close relationship to hippocampal-dependent cognitive impairment. In addition, $\mathrm{A} \beta_{\mathrm{pE} 3-40}$ and $\mathrm{A} \beta_{\mathrm{pE} 3-40} / \mathrm{t}$-tau showed modestly positive correlation with $A \beta$ PET SUVRs. In a previous study, $\mathrm{A} \beta 42 / \mathrm{t}$-tau ratios were also reported to have no correlation with A $\beta$ PET SUVRs, but have positive correlation with brain tau accumulation and longitudinal changes in hippocampal volume and cerebral glucose metabolism (54). Unlike $A \beta 42 / A \beta 40$ and $\mathrm{A} \beta 42 / \mathrm{t}$-tau in other studies, $\mathrm{A} \beta_{\mathrm{pE} 3-40} / \mathrm{t}$-tau modestly paralleled with the presence of cerebral amyloidosis in this study. Our findings of a positive relationship between $A \beta 42$ level and cognitive function measures are consistent with the findings of prior studies in which ultrasensitive detection methods were used, affirming the supposition that cognitive decline may be associated with low $\mathrm{A} \beta 42$ levels $(55,56)$, but not t-tau levels. There have been discordant findings regarding $\mathrm{A} \beta 42$ and $\mathrm{t}-$ tau levels correlating closely or not at all with cognitive test scores $(35,55,57-66)$, perhaps due to methodological differences related to study design and the quantitative methods used. $\mathrm{A} \beta_{\mathrm{pE}}$ has been reported to trigger AD-related neuronal loss, neurodegeneration, neurological deficits, and cognitive decline and has been shown to have differential expression patterns between AD progression and normal aging (19, 67-69). Similar to the finding indicating that a modified version of tau (i.e., ultrasensitive blood immunoassay-detected tau phosphorylated at threonine 181) (70) appears to be a better marker of disease progression than t-tau, $\mathrm{A} \beta_{\mathrm{pE}}$-related marker is a better biomarker of brain $A \beta$ burden and cognitive decline than $A \beta 42$ or $t$-tau, and may thus provide useful insights into brain functioning in the $\mathrm{AD}$ continuum.

Our ROC-AUC analyses indicated that $\mathrm{A} \beta_{\mathrm{pE} 3-40}(p=0.001)$, $\mathrm{A} \beta_{\mathrm{pE} 3-40} / \mathrm{t}$-tau $(p<0.001)$, and $\mathrm{A} \beta 42 / \mathrm{t}$-tau $(p=0.046)$ can be used to differentiate between individuals with $\mathrm{A} \beta \mathrm{PET}+$ and individuals with A $\beta$ PET-. Among the singular biomarkers, only $\mathrm{A} \beta_{\mathrm{pE} 3-40}$ had a significant and moderate-to-high predictive ability. Between the two aforementioned composite biomarkers, $\mathrm{A} \beta_{\mathrm{pE} 3-40} / \mathrm{t}$-tau yielded a higher AUC (0.83) as well as greater sensitivity (83.33\%) and specificity (75.00\%). Among the five biomarkers analyzed, $\mathrm{A} \beta_{\mathrm{pE} 3-40} / \mathrm{t}$-tau exhibited the best discriminatory power. Combining markers reflective of two distinct underlying pathophysiological derangements did indeed lead to an incremental benefit to between-group differentiation. There are differential time courses of $A \beta$ and tau changes in $\mathrm{AD}$ progression $(24,62)$. The better correspondence to $\mathrm{A} \beta$ PET findings for $\mathrm{A} \beta_{\mathrm{pE}}$, relative to other singular markers, may reflect $\mathrm{A} \beta_{\mathrm{pE}}$ being an earlier marker than $\mathrm{A} \beta 42$ or tau in $\mathrm{AD}$ pathogenesis (9). Although subjects with an early disease stage (i.e., healthy controls with $\mathrm{A} \beta \mathrm{PET}+$ ) were not enrolled in this study, it may be reasonable to pursue $A \beta_{\mathrm{pE} 3-40} / \mathrm{t}$-tau as a potential predictor of cerebral $A \beta$ deposition in population-based screening for high-risk individuals before $\mathrm{AD}$ symptom onset.

After controlling for demographic covariates, all of the presently examined putative biomarkers had some ability to predict $A \beta$ PET positivity, with the combination of $A \beta_{\mathrm{pE} 3-40}$ with t-tau appearing to be particularly useful for reflecting disease state along the AD continuum. Our ROC-AUC analyses indicated that $\mathrm{A} \beta_{\mathrm{pE} 3-40} / \mathrm{t}$-tau possessed higher $\mathrm{AUC}$, sensitivity, 
and specificity than $A \beta 42 / \mathrm{t}$-tau, supporting the notion that utilization of plasma $A \beta_{\mathrm{pE} 3-40}$ and t-tau together is superior to considering absolute levels of individual peptides or $A \beta 42 / \mathrm{t}$ tau ratio as markers of cerebral amyloidosis. In the face of the high cost and low accessibility of $\mathrm{A} \beta$ PET restricting wide use in clinical practice, $A \beta_{\mathrm{pE} 3-40} / \mathrm{t}$-tau may help support clinical decisions and be used as a clinical screening tool to rule out individuals who do not need costly $\mathrm{A} \beta \mathrm{PET}$ scanning in scenarios other than confirmatory diagnosis.

All patients in this study were classified into amnestic-type MCI or $\mathrm{AD}$ based on the clinical diagnostic criteria proposed by the 2011 NIA-AA workgroup (34). We intended to identify potential plasma biomarkers with proper cutoff values indicating $A \beta$ PET positivity over the normal-mild cognitive impairment$\mathrm{AD}$ cognitive spectrum, rather than to correlate clinical diagnoses with $\mathrm{A} \beta$ PET positivity or to differentiate clinical groups by $\mathrm{A} \beta$ PET positivity.

The current study had some limitations. First, we could only infer a possible association of plasma $\mathrm{A} \beta_{\mathrm{pE} 3-40}$ and t-tau with imminent risk of $A \beta$ PET positivity. Owing to small sample size and lack of $\mathrm{A} \beta+$ healthy controls, further replication, particularly with larger samples and longer follow-up, is warranted to validate the predictive values obtained in this study and to clarify the temporal relationship of these variables with $A \beta$ PET + . Second, the striatum was not included in the SUVR measurements for amyloid PET. Third, we did not account for comorbidity covariates that may affect plasma biomarker levels in our analyses. Finally, the relatively small sample size of our cohort limits the generalizability of the present findings.

\section{CONCLUSION}

In conclusion, a dual-factor biomarker consisting of the ratio between $\mathrm{A} \beta_{\mathrm{pE} 3-40}$ and t-tau measures, each determined by an ultrasensitive and easy-to-implement IMR assessment, showed superior performance characteristics and was in concordance with PET analysis and cognitive function assessment results. Given that $A \beta$ and tau have long been considered hallmarks of $\mathrm{AD}$ pathogenesis, it may be reasonable to pursue an $\mathrm{A} \beta_{\mathrm{pE} 3-40}$ and t-tau composite factor as a predictor of cerebral $A \beta$ deposition. $A \beta_{\mathrm{pE} 3-40} / \mathrm{t}$-tau might be an effective and feasible candidate for blood-based screening of cerebral AD-related neuropathology aimed at identifying at-risk individuals that should be recommended for CSF and/or PET studies prior to

\section{REFERENCES}

1. Masters CL, Simms G, Weinman NA, Multhaup G, McDonald BL, Beyreuther K. Amyloid plaque core protein in Alzheimer disease and Down syndrome. Proc Natl Acad Sci USA. (1985) 82:4245-9. doi: 10.1073/pnas.82.12.4245

2. Walsh DM, Selkoe DJ. Deciphering the molecular basis of memory failure in Alzheimer's disease. Neuron. (2004) 44:181-93. doi: 10.1016/j.neuron.2004.09.010

3. Geddes JW, Tekirian TL, Mattson MP. N-terminus truncated beta-amyloid peptides and C-terminus truncated secreted forms of amyloid precursor protein: distinct roles in the pathogenesis of Alzheimer's disease. Neurobiol Aging. (1999) 20:75-9; discussion 87. clinical treatment planning. These findings must be interpreted with caution given the relatively small sample size.

\section{DATA AVAILABILITY STATEMENT}

The raw data supporting the conclusions of this article will be made available by the authors, without undue reservation.

\section{ETHICS STATEMENT}

The studies involving human participants were reviewed and approved by Taipei Veterans General Hospital, Linkou Chang Gung Memorial Hospital, and Kaohsiung Chang Gung Memorial Hospital. The patients/participants provided their written informed consent to participate in this study.

\section{AUTHOR CONTRIBUTIONS}

T-BC and P-NW contributed to the conception and design of the study, acquisition of data, interpretation of the data, critical revision of the manuscript, and wrote the first draft of the manuscript. K-JL conducted PET imaging analysis. S-YL, Y-JL, $\mathrm{Y}-\mathrm{CL}$, and C-YW were involved in the collection and/or analysis of data. J-PC performed statistical analysis. All authors read and approved the submitted version.

\section{FUNDING}

This study was carried out with financial support from the Brain Research Center, National Yang-Ming University from The Featured Areas Research Center Program within the framework of the Higher Education Sprout Project by the Ministry of Education (MOE) in Taiwan, the Taiwan Alzheimer's Disease Neuroimaging Initiative (T-ADNI) group, the National Science Council and the Ministry of Science and Technology, Taiwan (MOST 105-2325-B-182A-005-, MOST 108-2321-B-010-013-MY2, and MOST 110-2321-B-010-007), Taipei Veterans General Hospital (V107C-090, V108C-060), and Chang Gung Memorial Hospital (CMRPG3D1802).

\section{ACKNOWLEDGMENTS}

We acknowledge the help of our staff and participants for their efforts and contributions. 
disease as new targets for the vaccination approach. J Neurochem. (2003) 85:1581-91. doi: 10.1046/j.1471-4159.2003.01818.x

8. Rijal Upadhaya A, Kosterin I, Kumar S, von Arnim CA, Yamaguchi H, Fändrich M, et al. Biochemical stages of amyloid- $\beta$ peptide aggregation and accumulation in the human brain and their association with symptomatic and pathologically preclinical Alzheimer's disease. Brain. (2014) 137(Pt. 3):887903. doi: 10.1093/brain/awt362

9. Moro ML, Phillips AS, Gaimster K, Paul C, Mudher A, Nicoll JAR, et al. Pyroglutamate and isoaspartate modified amyloid-beta in ageing and Alzheimer's disease. Acta Neuropathol Commun. (2018) 6:3. doi: 10.1186/s40478-017-0505-x

10. Mandler M, Walker L, Santic R, Hanson P, Upadhaya AR, Colloby SJ, et al. Pyroglutamylated amyloid- $\beta$ is associated with hyperphosphorylated tau and severity of Alzheimer's disease. Acta Neuropathol. (2014) 128:67-79. doi: 10.1007/s00401-014-1296-9

11. Neddens J, Daurer M, Flunkert S. Correlation of pyroglutamate amyloid $\beta$ and ptau Ser202/Thr205 levels in Alzheimer's disease and related murine models. PLoS ONE. (2020) 15:e0235543. doi: 10.1371/journal.pone.0235543

12. Jawhar $S$, Wirths $O$, Bayer TA. Pyroglutamate amyloid- $\beta$ (A $\beta$ ): a hatchet man in Alzheimer disease. J Biol Chem. (2011) 286:38825-32. doi: $10.1074 /$ jbc.R111.288308

13. Cynis H, Frost JL, Crehan H, Lemere CA. Immunotherapy targeting pyroglutamate-3 A $\beta$ : prospects and challenges. Mol Neurodegen. (2016) 11:48. doi: 10.1186/s13024-016-0115-2

14. Perez-Garmendia R, Gevorkian G. Pyroglutamate-modified amyloid beta peptides: emerging targets for Alzheimer's disease immunotherapy. Curr Neuropharmacol. (2013) 11:491-8. doi: 10.2174/1570159X11311050004

15. Nussbaum JM, Schilling S, Cynis H, Silva A, Swanson E, Wangsanut T, et al. Prion-like behaviour and tau-dependent cytotoxicity of pyroglutamylated amyloid- $\beta$. Nature. (2012) 485:651-5. doi: 10.1038/nature11060

16. Gunn AP, Masters CL, Cherny RA. Pyroglutamate-A $\beta$ : role in the natural history of Alzheimer's disease. Int J Biochem Cell Biol. (2010) 42:1915-8. doi: 10.1016/j.biocel.2010.08.015

17. Michno W, Nyström S, Wehrli P, Lashley T, Brinkmalm G, Guerard L, et al. Pyroglutamation of amyloid- $\beta \mathrm{x}-42(\mathrm{~A} \beta \mathrm{x}-42)$ followed by $\mathrm{A} \beta 1-40$ deposition underlies plaque polymorphism in progressing Alzheimer's disease pathology. J Biol Chem. (2019) 294:6719-32. doi: 10.1074/jbc.RA118.006604

18. Wang PN, Lin KJ, Liu HC, Andreasson U, Blennow K, Zetterberg H, et al. Plasma pyroglutamate-modified amyloid beta differentiates amyloid pathology. Alzheimers Dement. (2020) 12:e12029. doi: 10.1002/dad2.12029

19. Pivtoraiko VN, Abrahamson EE, Leurgans SE, DeKosky ST, Mufson EJ, Ikonomovic MD. Cortical pyroglutamate amyloid- $\beta$ levels and cognitive decline in Alzheimer's disease. Neurobiol Aging. (2015) 36:12-9. doi: 10.1016/j.neurobiolaging.2014.06.021

20. Jack CR Jr, Bennett DA, Blennow K, Carrillo MC, Dunn B, et al. NIA-AA research framework: toward a biological definition of Alzheimer's disease. Alzheimers Dement. (2018) 14:535-62. doi: 10.1016/j.jalz.2018.02.018

21. Dubois B, Feldman HH, Jacova C, Hampel H, Molinuevo JL, Blennow $\mathrm{K}$, et al. Advancing research diagnostic criteria for Alzheimer's disease: the IWG-2 criteria. Lancet Neurol. (2014) 13:614-29. doi: 10.1016/S1474-4422(14)70090-0

22. Shaw LM, Vanderstichele H, Knapik-Czajka M, Figurski M, Coart E, Blennow K, et al. Qualification of the analytical and clinical performance of CSF biomarker analyses in ADNI. Acta Neuropathol. (2011) 121:597-609. doi: 10.1007/s00401-011-0808-0

23. Pike KE, Savage G, Villemagne VL, Ng S, Moss SA, Maruff P, et al. Beta-amyloid imaging and memory in non-demented individuals: evidence for preclinical Alzheimer's disease. Brain. (2007) 130(Pt. 11):2837-44. doi: 10.1093/brain/awm238

24. Jack CR Jr, Holtzman DM. Biomarker modeling of Alzheimer's disease. Neuron. (2013) 80:1347-58. doi: 10.1016/j.neuron.2013.12.003

25. Villemagne VL, Burnham S, Bourgeat P, Brown B, Ellis KA, Salvado $\mathrm{O}$, et al. Amyloid $\beta$ deposition, neurodegeneration, and cognitive decline in sporadic Alzheimer's disease: a prospective cohort study. Lancet Neurol. (2013) 12:357-67. doi: 10.1016/S1474-4422(13) 70044-9

26. Sperling R, Donohue M, Raman R, Sun C-K, Yaari R, Siemers E, et al. The anti-amyloid treatment in asymptomatic Alzheimer's disease (A4) study: report of screening data results. Alzheimer's Dementia. (2018) 14:P215-6. doi: 10.1016/j.jalz.2018.06.2337

27. Karran E, Hardy J. Antiamyloid therapy for Alzheimer's disease-are we on the right road? N Engl J Med. (2014) 370:377-8. doi: 10.1056/NEJMe1313943

28. Shyu YI, Yip PK. Factor structure and explanatory variables of the MiniMental State Examination (MMSE) for elderly persons in Taiwan. J Formos Med Assoc. (2001) 100:676-83.

29. Chang CC, Kramer JH, Lin KN, Chang WN, Wang YL, Huang CW, et al. Validating the Chinese version of the Verbal Learning Test for screening Alzheimer's disease. J Int Neuropsychol Soc. (2010) 16:244-51. doi: 10.1017/S1355617709991184

30. Gong YX. Manual of Wechsler Memory Scale-Chinese Version: Changsha: Human Medical College Press (1989).

31. Chen TB, Lin CY, Lin KN, Yeh YC, Chen WT, Wang KS, et al. Culture qualitatively but not quantitatively influences performance in the Boston naming test in a chinese-speaking population. Dement Geriatr Cogn Dis Extra. (2014) 4:86-94. doi: 10.1159/000360695

32. Wang PN, Hong CJ, Lin KN, Liu HC, Chen WT. APOE $\varepsilon 4$ increases the risk of progression from amnestic mild cognitive impairment to Alzheimer's disease among ethnic Chinese in Taiwan. J Neurol Neurosurg Psychiatry. (2011) 82:165-9. doi: 10.1136/jnnp.2010.209122

33. Hughes CP, Berg L, Danziger WL, Coben LA, Martin RL. A new clinical scale for the staging of dementia. Br J Psychiatry. (1982) 140:566-72. doi: 10.1192/bjp.140.6.566

34. McKhann GM, Knopman DS, Chertkow H, Hyman BT, Jack CR Jr, et al. The diagnosis of dementia due to Alzheimer's disease: recommendations from the National Institute on Aging-Alzheimer's Association workgroups on diagnostic guidelines for Alzheimer's disease. Alzheimers Dement. (2011) 7:263-9. doi: 10.1016/j.jalz.2011.03.004

35. Chen TB, Lee YJ, Lin SY, Chen JP, Hu CJ, Wang PN, et al. Plasma Aß42 and total tau predict cognitive decline in amnestic mild cognitive impairment. Sci Rep. (2019) 9:13984. doi: 10.1038/s41598-019-50315-9

36. Emi M, Wu LL, Robertson MA, Myers RL, Hegele RA, Williams RR, et al. Genotyping and sequence analysis of apolipoprotein E isoforms. Genomics. (1988) 3:373-9. doi: 10.1016/0888-7543(88)90130-9

37. Lin KJ, Hsu WC, Hsiao IT, Wey SP, Jin LW, Skovronsky D, et al. Wholebody biodistribution and brain PET imaging with [18F]AV-45, a novel amyloid imaging agent-a pilot study. Nucl Med Biol. (2010) 37:497-508. doi: 10.1016/j.nucmedbio.2010.02.003

38. Hsiao IT, Huang CC, Hsieh CJ, Wey SP, Kung MP, Yen TC, et al. Perfusion-like template and standardized normalization-based brain image analysis using 18F-florbetapir (AV-45/Amyvid) PET. Eur J Nucl Med Mol Imaging. (2013) 40:908-20. doi: 10.1007/s00259-013-2350-x

39. Johnson KA, Sperling RA, Gidicsin CM, Carmasin JS, Maye JE, Coleman RE, et al. Florbetapir (F18-AV-45) PET to assess amyloid burden in Alzheimer's disease dementia, mild cognitive impairment, and normal aging. Alzheimers Dement. (2013) 9:S72-83. doi: 10.1016/j.jalz.2012.10.007

40. Ovod V, Ramsey KN, Mawuenyega KG, Bollinger JG, Hicks T, Schneider T, et al. Amyloid $\beta$ concentrations and stable isotope labeling kinetics of human plasma specific to central nervous system amyloidosis. Alzheimers Dement. (2017) 13:841-9. doi: 10.1016/j.jalz.2017.06.2266

41. Lui JK, Laws SM, Li QX, Villemagne VL, Ames D, Brown B, et al. Plasma amyloid-beta as a biomarker in Alzheimer's disease: the AIBL study of aging. J Alzheimers Dis. (2010) 20:1233-42. doi: 10.3233/jad-2010-090249

42. Vergallo A, Mégret L, Lista S, Cavedo E, Zetterberg H, Blennow K, et al. Plasma amyloid $\beta$ 40/42 ratio predicts cerebral amyloidosis in cognitively normal individuals at risk for Alzheimer's disease. Alzheimers Dement. (2019) 15:764-75. doi: 10.1016/j.jalz.2019.03.009

43. Janelidze S, Stomrud E, Palmqvist S, Zetterberg H, van Westen D, Jeromin A, et al. Plasma $\beta$-amyloid in Alzheimer's disease and vascular disease. Sci Rep. (2016) 6:26801. doi: 10.1038/srep26801

44. Schindler SE, Bollinger JG, Ovod V, Mawuenyega KG, Li Y, Gordon BA, et al. High-precision plasma $\beta$-amyloid 42/40 predicts current and future brain amyloidosis. Neurology. (2019) 93:e1647-59. doi: 10.1212/WNL.0000000000008081

45. Nakamura A, Kaneko N, Villemagne VL, Kato T, Doecke J, Doré V, et al. High performance plasma amyloid- $\beta$ biomarkers for Alzheimer's disease. Nature. (2018) 554:249-54. doi: 10.1038/nature25456 
46. Hameed S, Fuh JL, Senanarong V, Ebenezer EGM, Looi I, Dominguez JC, et al. Role of fluid biomarkers and PET imaging in early diagnosis and its clinical implication in the management of Alzheimer's disease. J Alzheimers Dis Rep. (2020) 4:21-37. doi: 10.3233/ADR-190143

47. Lopez OL, Klunk WE, Mathis CA, Snitz BE, Chang Y, Tracy RP, et al. Relationship of amyloid- $\beta 1-42$ in blood and brain amyloid: Ginkgo Evaluation of Memory Study. Brain Commun. (2019) 2:fcz038. doi: 10.1093/braincomms/fcz038

48. Doecke JD, Pérez-Grijalba V, Fandos N, Fowler C, Villemagne VL, Masters $\mathrm{CL}$, et al. Total $\mathrm{A} \beta(42) / \mathrm{A} \beta(40)$ ratio in plasma predicts amyloid-PET status, independent of clinical AD diagnosis. Neurology. (2020) 94:e1580-91. doi: 10.1212/WNL.0000000000009240

49. Schilling S, Zeitschel U, Hoffmann T, Heiser U, Francke M, Kehlen A, et al. Glutaminyl cyclase inhibition attenuates pyroglutamate Abeta and Alzheimer's disease-like pathology. Nat Med. (2008) 14:1106-11. doi: $10.1038 / \mathrm{nm} .1872$

50. Da Mesquita S, Papadopoulos Z, Dykstra T, Brase L, Farias FG, Wall $M$, et al. Meningeal lymphatics affect microglia responses and anti-A $\beta$ immunotherapy. Nature. (2021) 593:255-60. doi: 10.1038/s41586-021-03489-0

51. Mintun MA, Lo AC, Duggan Evans C, Wessels AM, Ardayfio PA, Andersen SW, et al. Donanemab in early Alzheimer's disease. N Engl J Med. (2021) 384:1691-704. doi: 10.1056/NEJMoa2100708

52. Russo C, Violani E, Salis S, Venezia V, Dolcini V, Damonte G, et al. Pyroglutamate-modified amyloid beta-peptides-AbetaN3(pE)-strongly affect cultured neuron and astrocyte survival. J Neurochem. (2002) 82:1480-9. doi: 10.1046/j.1471-4159.2002.01107.x

53. Breyhan H, Wirths O, Duan K, Marcello A, Rettig J, Bayer TA. APP/PS1KI bigenic mice develop early synaptic deficits and hippocampus atrophy. Acta Neuropathol. (2009) 117:677-85. doi: 10.1007/s00401-009-0539-7

54. Park JC, Han SH, Yi D, Byun MS, Lee JH, Jang S, et al. Plasma tau/amyloid- $\beta 1$ 42 ratio predicts brain tau deposition and neurodegeneration in Alzheimer's disease. Brain. (2019) 142:771-86. doi: 10.1093/brain/awy347

55. Hanon O, Vidal JS, Lehmann S, Bombois S, Allinquant B, Tréluyer $\mathrm{JM}$, et al. Plasma amyloid levels within the Alzheimer's process and correlations with central biomarkers. Alzheimers Dement. (2018) 14:858-68. doi: 10.1016/j.jalz.2018.01.004

56. Yaffe K, Weston A, Graff-Radford NR, Satterfield S, Simonsick EM, Younkin SG, et al. Association of plasma beta-amyloid level and cognitive reserve with subsequent cognitive decline. JAMA. (2011) 305:261-6. doi: 10.1001/jama.2010.1995

57. Cosentino SA, Stern Y, Sokolov E, Scarmeas N, Manly JJ, Tang MX, et al. Plasma B-amyloid and cognitive decline. Arch Neurol. (2010) 67:1485-90. doi: 10.1001/archneurol.2010.189

58. Llado-Saz S, Atienza M, Cantero JL. Increased levels of plasma amyloid-beta are related to cortical thinning and cognitive decline in cognitively normal elderly subjects. Neurobiol Aging. (2015) 36:2791-7. doi: 10.1016/j.neurobiolaging.2015.06.023

59. Mattsson N, Zetterberg H, Janelidze S, Insel PS, Andreasson U, Stomrud E, et al. Plasma tau in Alzheimer disease. Neurology. (2016) 87:1827-35. doi: 10.1212/WNL.0000000000003246

60. Chiu MJ, Chen YF, Chen TF, Yang SY, Yang FP, Tseng TW, et al. Plasma tau as a window to the brain-negative associations with brain volume and memory function in mild cognitive impairment and early Alzheimer's disease. Hum Brain Mapp. (2014) 35:3132-42. doi: 10.1002/hbm.22390

61. Tsai CL, Liang CS, Lee JT, Su MW, Lin CC, Chu HT, et al. Associations between plasma biomarkers and cognition in patients with Alzheimer's disease and amnestic mild cognitive impairment: a cross-sectional and longitudinal study. J Clin Med. (2019) 8:1893. doi: 10.3390/jcm8111893

62. Chen TB, Lai YH, Ke TL, Chen JP, Lee YJ, Lin SY, et al. Changes in plasma amyloid and tau in a longitudinal study of normal aging, mild cognitive impairment, and Alzheimer's disease. Dement Geriatr Cogn Disord. (2019) 48:180-95. doi: 10.1159/000505435

63. Hedden T, Oh H, Younger AP, Patel TA. Meta-analysis of amyloid-cognition relations in cognitively normal older adults. Neurology. (2013) 80:1341-8. doi: 10.1212/WNL.0b013e31828ab35d

64. Shekhar S, Kumar R, Rai N, Kumar V, Singh K, Upadhyay AD, et al. Estimation of tau and phosphorylated Tau181 in serum of Alzheimer's disease and mild cognitive impairment patients. PLoS ONE. (2016) 11:e0159099. doi: 10.1371/journal.pone.0159099

65. Pase M, Beiser A, Himali J, Satizabal C, Aparicio HJ, DeCarli C, et al. Plasma tau corresponds to preclinical Alzheimer's disease and is a strong predictor of future dementia (S48.001). Neurology. (2018) 90:S48.001.

66. Deters KD, Risacher SL, Kim S, Nho K, West JD, Blennow K, et al. Plasma tau association with brain atrophy in mild cognitive impairment and Alzheimer's disease. J Alzheimers Dis. (2017) 58:1245-54. doi: 10.3233/JAD161114

67. Wirths O, Breyhan H, Cynis H, Schilling S, Demuth HU, Bayer TA. Intraneuronal pyroglutamate-Abeta 3-42 triggers neurodegeneration and lethal neurological deficits in a transgenic mouse model. Acta Neuropathol. (2009) 118:487-96. doi: 10.1007/s00401-009-0557-5

68. Alexandru A, Jagla W, Graubner S, Becker A, Bäuscher C, Kohlmann $\mathrm{S}$, et al. Selective hippocampal neurodegeneration in transgenic mice expressing small amounts of truncated $\mathrm{A} \beta$ is induced by pyroglutamateA $\beta$ formation. J Neurosci. (2011) 31:12790-801. doi: 10.1523/JNEUROSCI. 1794-11.2011

69. Piccini A, Russo C, Gliozzi A, Relini A, Vitali A, Borghi R, et al. beta-amyloid is different in normal aging and in Alzheimer disease. J Biol Chem. (2005) 280:34186-92. doi: 10.1074/jbc.M501694200

70. Karikari TK, Pascoal TA, Ashton NJ, Janelidze S, Benedet AL, Rodriguez JL, et al. Blood phosphorylated tau 181 as a biomarker for Alzheimer's disease: a diagnostic performance and prediction modelling study using data from four prospective cohorts. Lancet Neurol. (2020) 19:422-33. doi: 10.1016/S1474-4422(20)30071-5

Conflict of Interest: The authors declare that the research was conducted in the absence of any commercial or financial relationships that could be construed as a potential conflict of interest.

Publisher's Note: All claims expressed in this article are solely those of the authors and do not necessarily represent those of their affiliated organizations, or those of the publisher, the editors and the reviewers. Any product that may be evaluated in this article, or claim that may be made by its manufacturer, is not guaranteed or endorsed by the publisher.

Copyright (C) 2021 Chen, Lin, Lin, Lee, Lin, Wang, Chen and Wang. This is an open-access article distributed under the terms of the Creative Commons Attribution License (CC BY). The use, distribution or reproduction in other forums is permitted, provided the original author(s) and the copyright owner(s) are credited and that the original publication in this journal is cited, in accordance with accepted academic practice. No use, distribution or reproduction is permitted which does not comply with these terms. 